\title{
“Co-construction" to "Symbiosis": Research on the Integrated Governance Mechanism of Industrial Colleges in Higher Vocational Colleges
}

\author{
Yan Wang* \\ Dean's Office, Chongqing Water Resources and Electric Engineering College, Chongqing 402160, China \\ *Corresponding author: Yan Wang, 452939216@qq.com
}

\begin{abstract}
Industrial colleges are the connection point between higher vocational colleges and enterprises to carry out in-depth collaborative education. At present, there are three forms of industrial colleges: surface cooperative industrial college focusing on order cooperation, middle-level industrial college relying on industry development, and deep cooperative industrial college with integrated development. There are several common problems among the three forms of industrial colleges, such as vague positioning, unclear division of responsibilities and rights between both parties, and "free riding" at all levels. In order to establish symbiotic industrial colleges, there is a need to change the concept first, then establish and improve the system, and finally, establish a cross-border teacher pool.
\end{abstract}

Keywords: Industrial college; School enterprise community of common destiny; Symbiotic development

Publication date: September 2021; Online publication: September 30, 2021

\section{Introduction}

Industrial colleges are the connection point between higher vocational colleges and enterprises to carry out in-depth collaborative education. They do not only play the role of a medium organism for the interaction between talent chain and industrial chain, but also the new derivative material for higher education in following the external adaptation law ${ }^{[1]}$. In 2020, the Ministry of Education issued the Guide for the Construction of Modern Industrial Colleges (Trial) (hereinafter referred to as the guide), which clearly pointed out that modern industrial colleges should aim to cultivate high-quality applied, compound, and innovative talents who adapt to and lead the development of modern industries. Their running bodies include colleges and universities with distinctive characteristics and close ties with local governments as well as industries that enterprises and other parties jointly build and manage. The guide formulated by the Ministry of Education for the construction of applied undergraduate modern industrial colleges also provides construction blueprints, ideas, and methods for higher vocational colleges to create representative industrial colleges.

\section{School-enterprise co-construction: The reality of the development of industrial colleges}

With strong support by the government, higher vocational colleges and enterprises have their respective resource advantages, using enterprises' technology chain, production chain, innovation chain, service chain, management chain, etc. as the scientific research teaching resources and service objects of the industrial academy. The co-construction of industrial colleges' co-management aims to cultivate talents that meet the needs of enterprises. At present, there are three types of cooperation mode of industrial colleges in higher vocational colleges, from "surface cooperation" to "in-depth cooperation." 


\subsection{Surface cooperation: Order-based industrial college}

Order-based industrial college is an upgraded version of "order class" and "naming class." The usual practice is to take a specialty as the support and embed a naming institution into a secondary college and department. It mainly carries out cooperation in regard to student training, teacher training, skill competition, enrollment, and employment publicity. Its characteristics include no increase in staffs, reduce enterprise investments, and reduce the difficulty in cooperation. Similarly, its disadvantages are also apparent: the interest demand point of the two sides is not established, the enthusiasm for in-depth integration is lacking, there are great difficulties in long-term cooperation, and there is only a small probability of forming influential achievements, especially for well-known enterprises in the industry.

\subsection{Middle level cooperation: Industrial college}

Industrial college is a new mode of industrial education integration with industrial characteristics formed by higher vocational colleges in combination with local regional strategic development. For example, by relying on the industrial advantages and characteristics of Jilin agricultural province, Changchun Vocational and Technical College cooperates with leading enterprises of local industries to jointly build a modern academy of agriculture and animal husbandry industry. Industrial colleges at this stage are usually led by higher vocational colleges along with the participation of local enterprises. The two sides gather advantageous resources and cooperate in practical teaching, social training, social services, teacher training, skill competition, and student employment in order to play a better role in promoting the local industrial development and talent supply.

\subsection{In-depth cooperation: Integrated industrial college}

Compared with industrial colleges, the dominant position of cooperative enterprises is more prominent. In terms of management system, the outlines for council or management committee are usually assumed. Compared with the first two cooperation modes, integrated industrial college enterprises do not only have much greater investment in capital and personnel, but also greater autonomy to participate in running schools. The specifications for talent training in industrial colleges at this stage are set according to the needs of industrial development, which are highly consistent with the development of industrial enterprises. Talent output, scientific research, and social services primarily serve the industry. The quality of talent training is high along with industry recognition.

\section{Dilemma diagnosis: Practical problems faced by industrial colleges and the causes}

With the construction of double colleges and universities, the integration of industries and education in higher vocational colleges are strengthened along with the enthusiasm of both schools and enterprises to jointly build industrial colleges. However, restricted by several external and internal factors, the construction of industrial colleges still faces practical difficulties in the process.

\subsection{Practical problems faced by industrial colleges}

\subsubsection{Vague orientation of industrial colleges}

From the existing cooperation mode, industrial colleges that are jointly built by higher vocational colleges and industrial enterprises have not broken the traditional cooperation mode and they do not have separate legal personality. On the one hand, industrial colleges assume a two-person sports model, which does not only include the introduction of enterprise capital and front-line technical talents, but also the investment in financial funds, school places, teaching staffs, and management teams of higher vocational colleges; thus, 
conflicts in regard to functional positioning and management mechanism may occur easily. On the other hand, the essence of capital and manpower that have been invested by enterprises are to pursue the maximization of profits, whereas education involves an organization which focuses on public welfare. The conflict of interests from both sides is inevitable. Finding a common point to meet the interests of enterprises along with ensuring the preservation of educational nature is a practical problem faced by integrated industrial colleges.

\subsubsection{Unclear division of responsibilities and rights}

At present, although a dual or diversified structure of property rights is assumed, the definition of property rights is still vague, especially when value-added income or future income on intangible assets that is generated by both or more investors cannot be divided. In terms of property division, the future value-added income generated by patented technologies, works, papers, and other intangible assets developed by teaching and scientific research teams in laboratories provided by schools or enterprises cannot be reasonably divided in the cooperation between both parties. In terms of benefit distribution, cooperative colleges transfer the training costs that have been incurred, such as material costs, labor costs for guiding students' internship and training, depreciation costs of training facilities and equipment, internship subsidies, benefits, as well as insurance paid to students, to cooperative enterprises when the original talent training objectives have been achieved. This increases the investment and risk of enterprises participating in the running of the schools. It also dampens the enthusiasm of enterprises to deeply participate in schoolenterprise cooperation.

\subsection{3. "Free riding" at all levels}

The phenomenon of "free riding" is common among various school running entities in industrial colleges. For example, in order to maximize their interests, enterprises would focus on enrollment, obtaining school or government awards, etc. In most cases, government departments such as the administrative park are not in control but only play supervisory roles. Even then, they do not assume the responsibilities to guide and supervise. The responsibilities of many main personnel in industrial colleges are scattered while the sense of responsibility to run the school cooperatively is weak. The actual responsibility of education finally falls on vocational colleges. The responsibilities of various school running entities in industrial colleges are scattered and they have a fluke mentality, which often leads to the phenomenon whereby the law is not responsible for the public.

\subsection{Causes of the practical problems faced by industrial colleges}

\subsubsection{Flawed local legal policy system}

As a systematic social project, the school-enterprise cooperation in vocational education does not only need the strong support of national and local policies, but also to be protected by perfect laws and regulations ${ }^{[2]}$. From the national level, a series of measures have been introduced to promote the integration of industries and education. However, in terms of specific implementation, the legal policy system for school-enterprise cooperation of vocational college by local governments at all levels has not been improved; there are no clear provisions on the functions undertaken and performed by local governments, management committees, and industrial associations. "As the main body of the school, to what extent should enterprises bear the obligations of running the school?" and "What punishments should they bear in case of a breach of contract?" have not been clearly defined by local governments. 


\subsubsection{Neglecting the establishment of a long-term mechanism for cooperation}

Industrial colleges are cooperative schools run by multiple entities. The largest restrictive factor affecting the establishment of a long-term mechanism is the difficulty in finding a common interest among multiple cooperative entities. From the perspective of interests, the fundamental goal of enterprises is to make profits, the fundamental goal of schools is to educate people, improve school running, and expand social influence, and the fundamental goal of the government is to promote local economic development. From the perspective of institutional constraints, vocational colleges are public institutions, where their properties and behaviors are restricted by national laws, regulations, rules, and ethics, while enterprises are often less constrained in performing their contracts.

\subsubsection{Insufficient demand for cooperation from both parties}

At present, the fundamental purposes of dual or multi-body participation in running schools are different. The purpose of enterprises participating in the running of schools in industrial colleges is to enjoy the preferential policies of national finance and taxation while receiving financial subsidies in order to reduce their operating costs ${ }^{[3]}$. At the same time, it provides priority to recruiting excellent graduates, greatly reducing the risk and cost of talent training, as well as laying the foundation for enterprise talent reserve. Several schools still have not changed their way of thinking when selecting or participating in the coconstruction of industrial college enterprises; there is a lack of fair, effective, and targeted comprehensive consideration selection methods, in which the subjective factors of the leaders have great impact on the selection results and the phenomenon of "marriage based on interest" is common. The docking based on external factors rather than internal needs makes it difficult to realize a long-term cooperation.

\section{Toward symbiosis: The construction path of integrated governance mechanism of industrial colleges}

\subsection{Concept transformation: The premise of symbiosis of industrial colleges}

In order to build an integrated industrial college, vocational colleges should first change the concept of integrating industries and education without overemphasizing the supply of human resources for enterprises, partially or even completely disregard the "education" function of vocational education, as well as adhere to the construction of an open, cooperative, service, and linkage education community.

\subsection{Sound system: The guarantee of symbiosis of industrial colleges}

In order to clarify the internal relationship of the organizational structure, integrated industrial colleges need to strengthen top-level designs, innovate their internal management system and mechanism, systematically design, scientifically layout, and clearly formulate the management system of people, talents, and affairs, smoothen the operation mechanism of teaching and scientific research management, as well as avoid hierarchical problems and contradictions between the school management system and industrial colleges.

\subsection{Integration of teachers: A bridge for symbiosis of industrial colleges}

Teachers are not only the bridge between vocational colleges and students, but also the key guarantee to promote the modernization of vocational education. Therefore, cross-border teachers are an unbreakable link or bridge to build integrated industrial colleges. They are also the biggest breakthrough for the integrated development of industrial colleges. Especially in the context of expanding enrollment to millions, the practical skills of teachers with profound theoretical knowledge but lack practical experiences should 
be improved, while employees from enterprises with high-level practical skills but lack theoretical skills should be included into the cross-border teacher pool, thus gradually forming teaching teams with distinctive characteristics.

\section{Funding}

This work was supported by the Fourth Batch of Comprehensive Education Reform Pilot Projects in Chongqing, Chongqing 2020 Humanities and Social Sciences Project (Project Number: 20sksz091).

\section{Disclosure statement}

The author declares that there is no conflict of interest.

\section{References}

[1] Zhao Z, Deng F, 2020, Logical Deconstruction and Breakthrough Dimension of Industrial College Research in Higher Vocational Colleges. Modern Education Management, (07): 102.

[2] Jin Z, Jia S, 2018, Reflection and Implementation Path of School Enterprise Cooperation in Vocational Education under the Background of the New Era. Vocational and Technical Education, (34): 54

[3] Kong S, 2020, The Causes and Management of School Enterprise Cooperation in Pluralistic Co Governance Vocational Education. Laboratory Research and Exploration, 39(02): 265. 